\title{
Higher flower and seed number leads to higher yield under water stress conditions imposed during reproduction in chickpea
}

\author{
Raju Pushpavalli ${ }^{\mathrm{A}, \mathrm{B}}$, Mainassara Zaman-Allah ${ }^{\mathrm{C}}$, Neil C. Turner $^{\mathrm{D}}$, Rekha Baddam $^{\mathrm{A}}$, \\ Mandali V. Rao ${ }^{\mathrm{B}}$ and Vincent Vadez ${ }^{\mathrm{A}, \mathrm{E}}$ \\ Anternational Crops Research Institute for the Semiarid Tropics, Crop Physiology Laboratory, \\ Patancheru 502 324, Telangana, India. \\ ${ }^{B}$ Department of Plant Sciences, Bharathidasan University, Tiruchirappalli 620024, Tamil Nadu, India. \\ ${ }^{\mathrm{C}}$ CIMMYT, PO Box MP 163, Mount Pleasant Harare, Zimbabwe. \\ DThe UWA Institute of Agriculture and Centre for Plant Genetics and Breeding, M080, \\ The University of Western Australia, 35 Stirling Highway, Crawley, WA 6009, Australia. \\ ${ }^{\mathrm{E}}$ Corresponding author. Email: v.vadez@cgiar.org
}

\begin{abstract}
The reproductive phase of chickpea (Cicer arietinum L.) is more sensitive to water deficits than the vegetative phase. The characteristics that confer drought tolerance to genotypes at the reproductive stage are not well understood; especially which characteristics are responsible for differences in seed yield under water stress. In two consecutive years, 10 genotypes with contrasting yields under terminal drought stress in the field were exposed to a gradual, but similar, water stress in the glasshouse. Flower number, flower + pod + seed abortion percentage, pod number, pod weight, seed number, seed yield, 100-seed weight (seed size), stem + leaf weight and harvest index (HI) were recorded in well watered plants (WW) and in water-stressed plants (WS) when the level of deficit was mild (phase I), and when the stress was severe (phase II). The WS treatment reduced seed yield, seed and pod number, but not flower + pod + seed abortion percentage or 100-seed weight. Although there were significant differences in total seed yield among the genotypes, the ranking of the seed yield in the glasshouse differed from the ranking in the field, indicating large genotype $\times$ environment interaction. Genetic variation for seed yield and seed yield components was observed in the WW treatment, which also showed differences across years, as well as in the WS treatment in both the years, so that the relative seed yield and relative yield components (ratio of values under WS to those under WW) were used as measures of drought tolerance. Relative total seed yield was positively associated with relative total flower number $\left(R^{2}=0.23\right.$ in year 2$)$ and relative total seed number $\left(R^{2}=0.83, R^{2}=0.79\right.$ in years 1 and 2 respectively). In phase I (mild stress), relative yield of seed produced in that phase was found to be associated with the flower number in both the years $\left(R^{2}=0.69, R^{2}=0.76\right.$ respectively). Therefore, the controlled drought imposition that was used, where daily water loss from the soil was made equal for all plants, revealed genotypic differences in the sensitivity of the reproductive process to drought. Under these conditions, the seed yield differences in chickpea were largely related to the capacity to produce a large number of flowers and to set seeds, especially in the early phase of drought stress when the degree of water deficit was mild.
\end{abstract}

Additional keywords: flower number, fraction of transpirable soil water, normalised transpiration ratio, pod number, seed number.

Received 6 May 2014, accepted 28 July 2014, published online 4 September 2014

\section{Introduction}

Chickpea, a cool-season food legume, has a global production of 13.1 Mt grown on 13.5 million ha (FAOSTAT 2013), second only to soybean. It is grown either on stored soil moisture after the rainy season (South Asia, eastern Africa, northeastern Australia), or in the rainy season itself (Canada and Mediterranean-climatic regions) (Berger et al. 2004). Whether grown on stored soil moisture or current rainfall, chickpea is exposed to terminal water shortage during the reproductive phase (Siddique et al. 2000; Turner 2003). In India, where $75 \%$ of the world's chickpeas are grown, the crop experiences severe drought during the reproductive phase as a result of the cultivated region having been displaced from the cooler, longerseason in the north to the hotter, dryer, and shorter-season in the south and east of the country (Gowda et al. 2009). Identification and understanding of parameters that result in improved drought tolerance is important in selection of parental lines for droughtprone areas.

The effect of water deficits at both the vegetative and reproductive phases of chickpea has been studied in both the field and the glasshouse conditions (Leport et al. 1998, 1999; Davies et al. 1999; Zaman-Allah et al. 2011b; Fang et al. 2010, 2011). Davies et al. (2000) and Leport et al. (2006) showed that flower and pod abortion, along with reduced pod production, 
limited chickpea seed yield during terminal drought stress. In most of the above mentioned studies, 1-6 genotypes were used and it is not clear whether all genotypes were exposed to similar rates of drying. Therefore a question remains whether the observed effects were actual sensitivity differences in the reproductive phase, or whether they were consequences of differences in the soil water status during the drying phase. In the current study, the application of a controlled slow progressive water deficit was imposed to ensure an equal availability of soil water for all genotypes throughout the stress treatment using a protocol (dry-down method) used earlier in chickpea (ZamanAllah et al. 2011a). This protocol minimises differences in water use due to differences in leaf area, conductance, or rooting. It also allowed us to distinguish between a phase of mild stress when the water loss of the water-stressed plants was between 100 and $50 \%$ of that in the fully irrigated plants, and a subsequent phase of severe stress when the water loss of the water stressed plants was less than $50 \%$ of that in the fully irrigated plants.

The objective of the study was to test whether there is genetic variation in the sensitivity of reproductive biology to a controlled water stress, and, if so, to assess the variables that lead to greater reproductive success under controlled water stress. The work was conducted on 10 chickpea genotypes that were previously observed to contrast for seed yield under terminal stress in the field (Krishnamurthy et al. 2010). More specific objectives were to: (i) assess flower and pod number and their abortion along with yield components of the chickpea genotypes during a phase of mild stress and the subsequent phase of severe water stress in comparison with the same genotypes given adequate water; (ii) test whether tolerant genotypes have different responses to the slow soil drying from sensitive genotypes during either or both of the two stress phases; and (iii) determine whether any parameter is linked directly or indirectly to higher yields in the water-deficit treatment.

\section{Materials and methods}

This study was conducted in the glasshouse at the International Crops Research Institute for the Semi-Arid Tropics (ICRISAT), Patancheru, India $\left(17^{\circ} 30^{\prime} \mathrm{N}, 78^{\circ} 16^{\prime} \mathrm{E}\right.$; altitude $549 \mathrm{~m}$ above sea level). Ten chickpea genotypes from ICRISAT's mini-core and reference collections (Upadhyaya and Ortiz 2001; Upadhyaya et al. 2008) were selected based on observed differences in yield under terminal drought conditions in the field at ICRISAT (Krishnamurthy et al. 2010) - five drought-sensitive (S) and five drought-tolerant (T) - ICC8058 (S), ICC4814 (S), ICC3776 (S), ICC7184 (S), ICC7323(S), ICC3325 (T), ICC867 (T), ICC8950 (T), ICC14799 (T), and ICC2263 (T). The genotypes came from a range of countries and had comparable times to flowering and maturity (see Table S1, available as Supplementary Material to this paper).

\section{Plant growth}

One hundred and fifty $275 \mathrm{~mm}$ diameter pots filled with $9 \mathrm{~kg}$ of autoclaved vertisol (fine montmorillontitic isohyperthermic typic pallustert) were sown with four seeds per pot after the seeds were treated with Thiram (Sudhama Chemicals Pvt. Ltd, Gujarat, India) to control seed-borne infections. In the first week of December 2009 and in the third week of December 2010, 15 pots were randomly assigned to each genotype. The maximum day/night temperature and $\mathrm{RH}$ was $28.5 / 15^{\circ} \mathrm{C}$ and $40 / 90 \%$ in year 1 and was $32 / 15^{\circ} \mathrm{C}$ and $35 / 85 \%$ in year 2 . The maximum and minimum VPD ranged between 0.2 and $2.3 \mathrm{KPa}$ in year 1 and 0.3 and $3.1 \mathrm{KPa}$ in year 2 .

All the pots were thinned to two plants per pot 14 days after sowing (DAS) and maintained well watered (WW) until the first flower had opened in all genotypes. Among the 15 pots per genotype, 12 pots with healthy similar-sized plants were selected for the experiment.

\section{Exposure to water deficit}

At flowering (50 DAS), the plants were exposed to two watering treatments: six replicate pots in each genotype were kept well watered (WW) and six replicate pots were water stressed (WS). All pots were watered to excess and allowed to drain overnight to field capacity. The following morning each pot was enclosed in a transparent plastic bag that was wrapped around the base of the stem to prevent evaporation from the soil and subsequently weighed at $100 \%$ field capacity. Thereafter, all pots were weighed each morning at 0900 hours Indian Standard Time (IST) and the rate of daily transpiration was calculated as the difference in weight between successive days. The experimental design was a randomised block design (RBD) with two treatments, WW and WS as the main factor, and genotypes as the sub-factor randomised in each main block.

To avoid waterlogging, the WW plants were maintained at $90 \%$ field capacity throughout the experiment. The WS treatment was imposed gradually by allowing the plants to lose only a maximum of $70 \mathrm{~g}$ of water per pot each day to avoid a too rapid imposition of water stress. Water loss $>70 \mathrm{~g} \mathrm{pot}^{-1} \mathrm{day}^{-1}$ was added back, as described by Vadez and Sinclair (2001). In this way, all the plants in the water-stressed treatment were reset to the same soil moisture content on each day of the experiment, regardless of their size and water use, until the water loss was $<70$ g pot $^{-1}$ day $^{-1}$. In fact, all the pots lost more than 70 g per day, so that the soil moisture declined at a very similar rate. It was only at later stages (phase II) that there were slight differences in the daily water losses but not sufficient to lead to major FTSW differences.

\section{Estimation of normalised transpiration ratio}

In order to compare the transpiration rate of the WS plants to the fully irrigated (WW) controls, the transpiration data was subjected to two normalisations (see Vadez and Sinclair 2001). First the transpiration ratio was calculated:

$$
\begin{aligned}
\mathrm{TR} i j= & \text { transpiration rate of plant } i \text { in genotype } j / \\
& \text { mean transpiration rate of } \mathrm{WW} \text { of genotype } j,
\end{aligned}
$$

where TR $i j$ is the daily transpiration ratio.

Then to minimise the differences in plant size within a genotype, the transpiration ratios of each day for each individual plant was divided by the mean TR of the first 3 days, i.e. before there was any stress. The normalised transpiration ratios, NTR $i$, were then:

$$
\text { NTR } i=\text { TRiday } n / \text { mean TRidays } 1-3
$$


Once the transpiration rate had started to decrease compared with the fully irrigated controls, that is when the NTR values fell below 1.0, the water stress treatment was divided into two phases based on the NTR values: phase I was when the NTR values were between 1.0 and 0.5 (100 and 50\% of the irrigated controls), i.e. a mild stress, and phase II was when the NTR values were between 0.49 and 0.10 (49-10\% of the irrigated controls), i.e. a severe stress. Based on a typical drydown curve (data not shown), the transition from the non-stress to phase I (NTR falls below 1) was therefore when the fraction of transpirable soil water (FTSW, see below for calculation) was between 50 and 60\%). The transition from phase I to phase II occurred at a FTSW between 20 and 30\% FTSW. By definition of the NTR at the end of phase II there was no more transpirable soil water in the pots and therefore the FTSW was down to zero. No leaf water potentials were taken. The exposure to water stress was terminated for each genotype when the NTR value of the WS plants fell below 0.1 , i.e. when the transpiration of WS plants was less than $10 \%$ of that in WW plants and when it was assumed that stomata were fully closed (Sinclair and Ludlow 1985). Once the NTR values of the WS plants had dropped below 0.1 (79-85 DAS in year 1 and 81-87 DAS in year 2), they were given one amount of $400 \mathrm{~mL}$ of water to stop the stress treatment, whereas no water was given to WW plants. This amount represented $18 \%$ of the water required to bring the soil to $100 \% \mathrm{FC}$ and insufficient to allow any regrowth or flowering. The purpose was not to attempt a recovery phase but to let the plants mature and completely dry before harvest 15-21 days later in year 1 and 11-17 days later in year 2. In any case, at this stage flowering had ceased and this period of the crop cycle had no bearing on the final yield results.

\section{Estimation of fraction of transpirable soil water (FTSW) and relationship with transpiration}

The fraction of transpirable soil water (FTSW) was backcalculated for each day of the experiment after the water stress was relieved. FTSW is the fraction of water available in the soil for plant transpiration between the stage when the soil is at field capacity and that when transpiration has become negligible and when it was considered there was no longer any water available for transpiration, i.e. when the NTR was below 0.1 . Therefore the FTSW is set at 1 when the soil is at field capacity (100\%) and 0 when NTR falls below 0.1 . The difference in pot weight between field capacity (the first weighing of pots) and $\mathrm{FTSW}=0$ (the pot weight when NTR reaches 0.1 ) provides the total transpirable soil water (TTSW) of the pot. TTSW is then used to calculate daily FTSW on any day ' $n$ ' such as:

$$
\text { FTSW }_{\mathrm{n}}=1-\left(\text { weight }_{\mathrm{FC}}-\text { weight }_{\text {day }}\right) / \text { TTSW, }
$$

where weight $\mathrm{FC}_{\mathrm{FC}}$ and weight $\mathrm{day}_{\mathrm{n}}$ are the pot weight at field capacity and on every single day ' $n$ '.

For each plant of a genotype, the daily NTR values were plotted as a function of FTSW value. A plateau regression procedure (Ray and Sinclair 1998) was used to determine the FTSW threshold (t) when NTR began to decrease $i$ for each genotype. The plateau regression procedure carried out iterations of the NTR data starting at FTSW = 1 (wet soil) and fitted them to $y=1$ equation. When $y=1$ was no longer the best fit for the response of NTR to FTSW, data were fitted to a linear decline equation. The FTSW threshold (with confidence interval) at which NTR began to decrease was taken as the intersection between the plateau $(y=1)$ and the linear decline equation.

\section{Parameters measured}

Each flower that developed was identified daily with a short piece of wool thread placed at the node; different colour threads were used in Phase I and Phase II in the WS treatment. When 90-95\% plants of a given genotype in the WS treatment entered into phase II, the colour of the thread was also changed in the WW plants of the corresponding genotype, thus, dividing the WW treatment into phase I and phase II for comparison of each phase across water regimes. Identification of flowers with the threads was discontinued in the WW treatment at the end of phase II. The plants were harvested at maturity after complete drying (101 DAS in 2009-2010, 104 DAS in 2010-2011) by cutting the plants at soil level and oven-dried at $65^{\circ} \mathrm{C}$ for $48 \mathrm{~h}$ before measurement of the plant components. The stem +leaf weight was separated for each plant per pot and the mean calculated per pot. Flowers were counted from the number of threads in each phase. At harvest, the threads and corresponding pod were put into one of the two categories: (i) threads where no pod was present or the pods were empty or had only undeveloped seeds, and (ii) threads with large pods containing one or two seeds (chickpea has a maximum of two seeds per pod). Category (i) represented the flower + pod + seed abortion, and category (ii) represented the fertile pods with complete seed development. The seed number was recorded by hand threshing the fertile pods in category (ii) and subsequently weighed to obtain seed weight from each pot of each genotype and treatment. The seed weight obtained from flowers and pods identified in phase I, phase II and their sum are mentioned as 'phase I seed yield', 'phase II seed yield' and 'total seed yield' respectively. Except for the stem + leaf weight and the harvest index, the seed and pod parameters were measured separately for phase I and phase II. All the parameters that were evaluated separately in phase I, phase II and their sum (phase I+ phase II) were prefixed with the terms phase I, phase II and total. The 100-seed weight was calculated by dividing the seed yield by the seed number and multiplied by 100 (total, phase I and II). The harvest index at maturity was calculated from the ratio of total seed yield to total aboveground plant dry weight. The total flower + pod + seed abortion percentage was calculated by dividing threads in category (i) where no pods or pods with no or small pods were recorded by total thread (total flower) number multiplied by 100 .

\section{Statistical analysis}

The data were analysed using GENSTAT 12.0 (VSN International Ltd, Hemel Hempstead, UK) where an Unbalanced Analysis of Variance was conducted for all observed parameters. To calculate FTSW threshold SAS 9.2 software (SAS Institute, Cary, NC, USA) was used. Differences between mean values of treatments were evaluated using the least significant difference (l.s.d.) at a 0.05 significance level. The data were plotted and linear regressions were fitted using Microsoft Excel 2007 (Microsoft Corp., Redmond, WA, USA). 


\section{Results}

\section{Development of water stress}

Phases I and II were longer in year 2 than in year 1 (Table 1). In year 1 , the mean duration across genotypes of phase I and

Table 1. Number of days that the chickpea genotypes were exposed to soil drying in phase I (normalised transpiration rate (NTR) from 1.0 to 0.5 ) and phase II (NTR from 0.49 to 0.10 ) and the fraction of transpirable soil water (FTSW) threshold value for transpiration decline in years 1 and 2

The s.e. and $95 \%$ confidence limits of FTSW are provided

\begin{tabular}{lrcccc}
\hline Genotype & $\begin{array}{c}\text { No. of } \\
\text { days in } \\
\text { phase I }\end{array}$ & $\begin{array}{c}\text { No. of } \\
\text { days in } \\
\text { phase II }\end{array}$ & $\begin{array}{c}\text { FTSW } \\
\text { threshold } \\
\text { value }\end{array}$ & $\begin{array}{c}\text { Estimate } \\
\text { s.e. }\end{array}$ & $\begin{array}{c}95 \% \\
\text { confidence } \\
\text { limits }\end{array}$ \\
\hline Year 1 & & & & & \\
ICC 867 (T) & 12 & 10 & 0.64 & 0.02 & $0.59-0.68$ \\
ICC 2263 (T) & 11 & 10 & 0.64 & 0.03 & $0.58-0.69$ \\
ICC 14799 (T) & 9 & 12 & 0.68 & 0.02 & $0.64-0.72$ \\
ICC 3325 (T) & 10 & 11 & 0.66 & 0.02 & $0.61-0.70$ \\
ICC 8950 (T) & 11 & 12 & 0.56 & 0.03 & $0.49-0.62$ \\
ICC 7323 (S) & 12 & 11 & 0.64 & 0.03 & $0.57-0.69$ \\
ICC 7184 (S) & 12 & 13 & 0.50 & 0.03 & $0.44-0.55$ \\
ICC 4814 (S) & 12 & 8 & 0.83 & 0.05 & $0.73-0.94$ \\
ICC 8058 (S) & 9 & 15 & 0.72 & 0.03 & $0.66-0.76$ \\
ICC 3776 (S) & 9 & 10 & 0.72 & 0.03 & $0.67-0.78$ \\
Year 2 & & & & & \\
ICC 867 (T) & 21 & 15 & 0.67 & 0.03 & $0.60-0.73$ \\
ICC 2263 (T) & 19 & 16 & 0.73 & 0.04 & $0.64-0.82$ \\
ICC 14799 (T) & 18 & 13 & 0.71 & 0.02 & $0.67-0.75$ \\
ICC 3325 (T) & 19 & 17 & 0.69 & 0.03 & $0.62-0.75$ \\
ICC 8950 (T) & 18 & 17 & 0.76 & 0.04 & $0.68-0.84$ \\
ICC 7323 (S) & 19 & 17 & 0.76 & 0.04 & $0.68-0.83$ \\
ICC 7184 (S) & 22 & 15 & 0.44 & 0.04 & $0.36-0.51$ \\
ICC 4814 (S) & 19 & 16 & 0.86 & 0.04 & $0.78-0.94$ \\
ICC 8058 (S) & 17 & 14 & 0.80 & 0.03 & $0.74-0.86$ \\
ICC 3776 (S) & 19 & 17 & 0.78 & 0.03 & $0.71-0.85$ \\
\hline
\end{tabular}

phase II was 11 days, whereas in year 2, phase II was shorter by an average of 3 days (Table 1). The FTSW threshold values when NTR began to decrease varied between 0.56 and 0.83 in year 1 and between 0.67 and 0.86 in year 2 . There was no significant difference in the threshold values between the putatively tolerant group and putatively sensitive group of genotypes from the field evaluation and no significant correlation between the threshold values and drought tolerance (relative yield in the glasshouse) among the genotypes in either year 1 $\left(R^{2}=0.12\right)$ or in year $2\left(R^{2}=0.09\right)$ (data not shown).

\section{Comparisons across years and stress phases}

When averaged across the 10 genotypes, phase II flower number, phase II seed number and phase II seed yield were lower than in phase I in the WW treatment in year 2 and in the WS treatment in both the years, indicating that values of the reproductive stage parameters, except the total 100 -seed weight, decreased with time, even under WW conditions (Fig. 1). There was also a year effect in these results. However, the differences between phase I and phase II were greater in the WS treatment, indicating a specific effect of the severe stress treatment on parameters (flower number, seed number and seed yield), particularly in year 2 (Fig. 1). The phase I flower + pod + seed abortion percentage was greater in the WS treatment than in the WW treatment only in year 1 (Fig. 1).

\section{Genotype and genotype $\times$ year interaction}

Although the experiments were conducted in a controlledenvironment glasshouse during both years, there were significant genotype $\times$ year interactions for most parameters (Table 2), indicating that the conditions in the 2 years of experiment were very different. In the WW treatment, the genotype and genotype $\times$ year interactions were significant for all parameters in both phases except for phase II 100-seed weight, and the phase II seed yield varied among genotypes

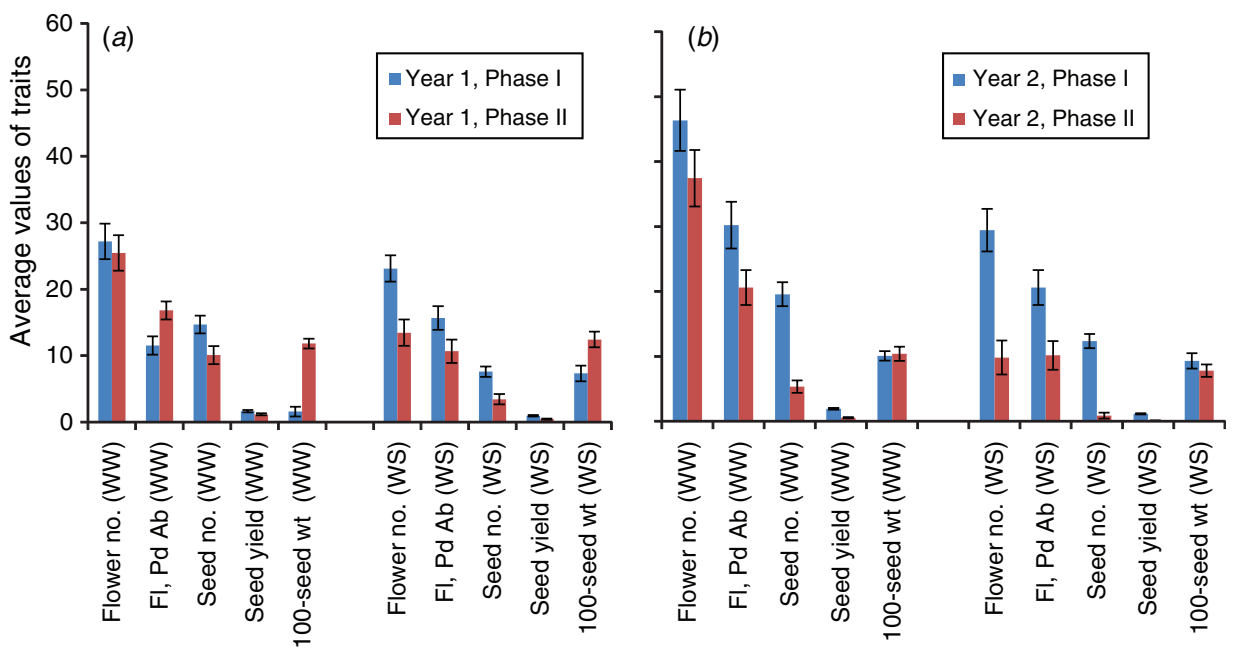

Fig. 1. Mean values (of all 10 chickpea genotypes) and standard error (s.e.) of mean for flower number pot ${ }^{-1}$, flower $+\operatorname{pod}+$ seed abortion number $\operatorname{pot}^{-1}(\mathrm{Fl}, \mathrm{Pd} \mathrm{Ab})$, seed number $\operatorname{pot}^{-1}$, seed yield $\left(\mathrm{g} \mathrm{pot}^{-1}\right)$, and 100 -seed weight $\left(\mathrm{g} \mathrm{pot}^{-1}\right)$ at two phases (light grey-Phase I, dark grey-Phase II) in the well-watered (WW) and water-stressed (WS) treatments during year $1(a)$ and year $2(b)$. 
Table 2. $F$-probability values (at $P<0.01$ ) and $F$-statistic values obtained with unbalanced ANOVA analysis for chickpea genotype, year and the genotype $\times$ year interaction for flower number, flower + pod + seed abortion percentage, pod number, pod weight, seed number, seed yield and100-seed weight in phase I and phase II for years 1 and 2

WW, well watered; WS, water stressed

\begin{tabular}{|c|c|c|c|c|c|c|c|c|}
\hline Detail & Interaction & $\begin{array}{l}\text { Flower } \\
\text { number }\end{array}$ & $\begin{array}{l}\text { Flower }+ \text { pod }+ \\
\text { seed abortion } \%\end{array}$ & $\begin{array}{c}\text { Pod } \\
\text { number }\end{array}$ & $\begin{array}{c}\text { Pod } \\
\text { weight }\end{array}$ & $\begin{array}{l}\text { Seed } \\
\text { number }\end{array}$ & $\begin{array}{l}\text { Seed } \\
\text { yield }\end{array}$ & $\begin{array}{c}100 \text { seed } \\
\text { weight }\end{array}$ \\
\hline \multicolumn{9}{|l|}{$\overline{W W}$} \\
\hline Phase I & $\begin{array}{l}\text { Genotype } \\
\text { Year }\end{array}$ & $\begin{array}{l}<0.001 \\
<0.001\end{array}$ & $\begin{array}{l}<0.001 \\
<0.001\end{array}$ & $\begin{array}{r}<0.001 \\
0.002\end{array}$ & $\begin{array}{r}<0.001 \\
0.002\end{array}$ & $\begin{array}{r}<0.001 \\
0.002\end{array}$ & $\begin{array}{r}<0.001 \\
0.074\end{array}$ & $\begin{array}{r}<0.001 \\
0.002\end{array}$ \\
\hline$F$-statistic & $\begin{array}{c}\text { Genotype } \times \text { year } \\
\text { Genotype } \\
\text { Genotype } \times \text { year }\end{array}$ & $\begin{array}{c}<0.001 \\
6.35 \\
7.63\end{array}$ & $\begin{array}{c}<0.001 \\
4.50 \\
7.42\end{array}$ & $\begin{array}{c}<0.001 \\
6.68 \\
3.77\end{array}$ & $\begin{array}{l}<0.001 \\
12.2 \\
4.09\end{array}$ & $\begin{array}{c}<0.001 \\
10.47 \\
6.62\end{array}$ & $\begin{array}{c}<0.001 \\
12.89 \\
4.01\end{array}$ & $\begin{array}{c}<0.001 \\
17.39 \\
4.29\end{array}$ \\
\hline Phase II & $\begin{array}{l}\text { Genotype } \\
\text { Year }\end{array}$ & $\begin{array}{r}0.044 \\
<0.001\end{array}$ & $\begin{array}{r}0.009 \\
<0.001\end{array}$ & $\begin{array}{l}0.006 \\
0.034\end{array}$ & $\begin{array}{l}<0.001 \\
<0.001\end{array}$ & $\begin{array}{l}<0.001 \\
<0.001\end{array}$ & $\begin{array}{l}<0.001 \\
<0.001\end{array}$ & $\begin{array}{c}<0.001 \\
0.26\end{array}$ \\
\hline$F$-statistic & $\begin{array}{l}\text { Genotype } \times \text { year } \\
\text { Genotype } \\
\text { Genotype } \times \text { year }\end{array}$ & $\begin{array}{c}<0.001 \\
2.09 \\
4.05\end{array}$ & $\begin{array}{l}0.001 \\
3.09 \\
4.32\end{array}$ & $\begin{array}{l}0.003 \\
2.93 \\
3.17\end{array}$ & $\begin{array}{l}0.004 \\
5.47 \\
3.14\end{array}$ & $\begin{array}{l}0.002 \\
5.55 \\
3.45\end{array}$ & $\begin{array}{l}0.005 \\
4.46 \\
3.04\end{array}$ & $\begin{array}{l}0.16 \\
5.91 \\
1.13\end{array}$ \\
\hline \multicolumn{9}{|l|}{$W S$} \\
\hline Phase I & $\begin{array}{c}\text { Genotype } \\
\text { Year }\end{array}$ & $\begin{array}{l}0.002 \\
0.005\end{array}$ & $\begin{array}{l}0.19 \\
0.02\end{array}$ & $\begin{array}{r}<0.001 \\
0.002\end{array}$ & $\begin{array}{r}<0.001 \\
0.001\end{array}$ & $\begin{array}{l}<0.001 \\
<0.001\end{array}$ & $\begin{array}{r}<0.001 \\
0.007\end{array}$ & $\begin{array}{r}0.008 \\
<0.001\end{array}$ \\
\hline$F$-statistic & $\begin{array}{c}\text { Genotype } \times \text { year } \\
\text { Genotype } \\
\text { Genotype } \times \text { year }\end{array}$ & $\begin{array}{c}<0.001 \\
3.46 \\
4.72\end{array}$ & $\begin{array}{c}<0.001 \\
1.47 \\
4.39\end{array}$ & $\begin{array}{c}<0.001 \\
6.99 \\
2.31\end{array}$ & $\begin{array}{c}0.004 \\
17.14 \\
3.11\end{array}$ & $\begin{array}{c}0.001 \\
11.68 \\
3.58\end{array}$ & $\begin{array}{c}0.005 \\
17.23 \\
3.00\end{array}$ & $\begin{array}{l}0.25 \\
2.81 \\
1.31\end{array}$ \\
\hline Phase II & $\begin{array}{l}\text { Genotype } \\
\text { Year }\end{array}$ & $\begin{array}{l}0.18 \\
0.04\end{array}$ & $\begin{array}{l}0.17 \\
0.72\end{array}$ & $\begin{array}{r}0.033 \\
<0.001\end{array}$ & $\begin{array}{r}0.001 \\
<0.001\end{array}$ & $\begin{array}{l}<0.001 \\
<0.001\end{array}$ & $\begin{array}{l}<0.001 \\
<0.001\end{array}$ & $\begin{array}{l}0.86 \\
0.05\end{array}$ \\
\hline$F$-statistic & $\begin{array}{c}\text { Genotype } \times \text { year } \\
\text { Genotype } \\
\text { Genotype } \times \text { year }\end{array}$ & $\begin{array}{l}0.18 \\
1.47 \\
1.47\end{array}$ & $\begin{array}{l}0.24 \\
1.38 \\
1.25\end{array}$ & $\begin{array}{c}<0.001 \\
2.20 \\
3.99\end{array}$ & $\begin{array}{c}<0.001 \\
3.52 \\
6.63\end{array}$ & $\begin{array}{c}<0.001 \\
3.76 \\
6.68\end{array}$ & $\begin{array}{c}<0.001 \\
3.91 \\
6.73\end{array}$ & $\begin{array}{l}0.49 \\
0.51 \\
0.94\end{array}$ \\
\hline
\end{tabular}

under WW condition in both the years (Table 2). The $F$-statistic value suggests that the interaction effect between genotype and year had an effect that was equal or larger than the effect of genotype on phase I and phase II flower + pod + seed abortion percentage and phase I and phase II flower number in the WW treatment, indicating a strong influence of the year on these parameters. For the other yield components in phase I and phase II (pod and seed number, pod weight and seed yield, but not 100 -seed weight) the genotype $\times$ year interactions were also significant, but the $F$-statistic values were larger for the genotype component indicating these variables were strongly affected by the genotype. In summary, the 2 years offered different conditions to the trials, which affected some aspects of the experiment, but it was most significantly the genotypic effects that were dominant in the variations.

In the WS treatment, the genotypes differed significantly for all parameters except phase II flower number and phase I and phase II flower + pod + seed abortion percentage. The interaction between genotype $\times$ year was not significant for phase I and phase II 100-seed weight and for phase II flower number and phase II flower+pod+seed abortion number. The $F$-statistic values suggested strong genotype $\times$ year interaction effects on the phase I and phase II flower + pod + seed abortion percentage and on the phase I flower number. The $F$-statistic value suggests that the relative stem + leaf weight, relative total seed number, relative phase I pod weight were determined by genotype $\times$ year interaction effects, whereas relative total pod weight, relative harvest index, relative phase I flower number and relative phase II flower + pod + seed abortion percentage were determined largely by the genetic component.

\section{Genotype and genotype $\times$ treatment interaction}

The genotypes varied significantly for all parameters in phase I in both years and the WS treatment has a significant effect on all parameters except phase I flower number in year 1. However, the genotype $\times$ treatment interaction was not significant in year 1 for any parameter, and in year 2 , although the genotype $\times$ treatment interaction were significant (Table 3 ), the $F$-statistic values were higher for the genotype component, indicating that variation in the different parameters was strongly driven by the genetic component.

As the genotypes varied significantly under both WW and WS treatments in both years and no or limited genotype $x$ treatment interaction was found, the variation in the WS treatment might be the result of differences in the WW treatment. Therefore, we calculated the relative values (WS/ WW) of the parameters to remove possible differences among the genotypes under WS conditions that might arise from differences in the WW treatment. The absolute (in the WS treatment) and relative values of total seed yield (Table 4) and phase I and phase II seed yield (Table S3) were ranked in the order of high to low seed yield. This was to assess whether the high yielding genotypes in the WS treatment had high potential yields (high yields in the WW conditions) and whether they showed any similarity to the drought tolerance 
Table 3. F probability values (at $P<0.01$ ) and $F$-statistic obtained with unbalanced ANOVA analysis for genotype, treatment and the genotype $\times$ treatment interaction for flower number, flower + pod + seed abortion $\%$, pod number, pod weight, seed number, seed yield and 100-seed weight in phase I and phase II for years 1 and 2

\begin{tabular}{|c|c|c|c|c|c|c|c|c|}
\hline & Interaction & $\begin{array}{l}\text { Flower } \\
\text { number }\end{array}$ & $\begin{array}{l}\text { Flower }+ \text { pod }+ \\
\text { seed abortion } \%\end{array}$ & $\begin{array}{c}\text { Pod } \\
\text { number }\end{array}$ & $\begin{array}{c}\text { Pod } \\
\text { weight }\end{array}$ & $\begin{array}{c}\text { Seed } \\
\text { number }\end{array}$ & $\begin{array}{l}\text { Seed } \\
\text { yield }\end{array}$ & $\begin{array}{c}100 \text { seed } \\
\text { weight }\end{array}$ \\
\hline \multicolumn{9}{|l|}{ Year 1} \\
\hline \multirow[t]{3}{*}{ Phase I } & Genotype & $<0.001$ & $<0.001$ & $<0.001$ & $<0.001$ & $<0.001$ & $<0.001$ & 0.001 \\
\hline & Treatment & 0.067 & 0.005 & $<0.001$ & $<0.001$ & $<0.001$ & $<0.001$ & 0.001 \\
\hline & Genotype $\times$ treatment & 0.497 & 0.107 & 0.551 & 0.218 & 0.216 & 0.412 & 0.154 \\
\hline \multirow[t]{2}{*}{$F$-statistic } & Genotype & 3.95 & 3.87 & 3.65 & 7.38 & 5.46 & 7.81 & 3.50 \\
\hline & Genotype $\times$ treatment & 0.94 & 0.90 & 0.88 & 1.37 & 1.38 & 1.05 & 1.54 \\
\hline \multirow[t]{3}{*}{ Phase II } & Genotype & 0.064 & 0.309 & 0.018 & $<0.001$ & $<0.001$ & $<0.001$ & 0.002 \\
\hline & Treatment & $<0.001$ & $<0.001$ & $<0.001$ & $<0.001$ & $<0.001$ & $<0.001$ & 0.551 \\
\hline & Genotype $\times$ treatment & 0.133 & 0.139 & 0.742 & 0.681 & 0.504 & 0.962 & 0.671 \\
\hline \multirow[t]{2}{*}{$F$-statistic } & Genotype & 1.92 & 1.64 & 2.45 & 6.33 & 7.68 & 6.59 & 3.31 \\
\hline & Genotype $\times$ treatment & 1.60 & 2.80 & 0.66 & 0.73 & 0.93 & 0.33 & 0.74 \\
\hline \multicolumn{9}{|l|}{ Year 2} \\
\hline \multirow[t]{3}{*}{ Phase I } & Genotype & $<0.001$ & $<0.001$ & $<0.001$ & $<0.001$ & $<0.001$ & $<0.001$ & $<0.001$ \\
\hline & Treatment & $<0.001$ & $<0.001$ & $<0.001$ & $<0.001$ & $<0.001$ & $<0.001$ & 0.052 \\
\hline & Genotype $\times$ treatment & 0.025 & 0.040 & 0.006 & 0.001 & 0.006 & 0.002 & 0.196 \\
\hline \multirow[t]{2}{*}{$F$-statistic } & Genotype & 11.11 & 6.80 & 13.43 & 21.72 & 20.04 & 23.3 & 8.14 \\
\hline & Genotype $\times$ treatment & 2.34 & 1.78 & 2.93 & 3.00 & 2.90 & 3.43 & 1.43 \\
\hline \multirow[t]{3}{*}{ Phase II } & Genotype & $<0.001$ & $<0.001$ & $<0.001$ & $<0.001$ & $<0.001$ & $<0.001$ & 0.134 \\
\hline & Treatment & $<0.001$ & $<0.001$ & $<0.001$ & $<0.001$ & $<0.001$ & $<0.001$ & 0.153 \\
\hline & Genotype $\times$ treatment & 0.077 & 0.132 & 0.001 & $<0.001$ & 0.001 & $<0.001$ & 0.496 \\
\hline \multirow[t]{2}{*}{$F$-statistic } & Genotype & 3.71 & 3.92 & 5.03 & 8.49 & 6.94 & 7.82 & 1.69 \\
\hline & Genotype $\times$ treatment & 1.85 & 1.82 & 3.65 & 5.20 & 3.64 & 4.27 & 0.93 \\
\hline
\end{tabular}

Table 4. Ranking of genotype for mean total seed yield in the water-stressed (WS) treatment and the mean relative total seed yield values obtained by dividing WS value by well-watered (WW) value in years 1 and 2

$\mathrm{T}$, tolerant; S, sensitive; NA, not applicable

\begin{tabular}{lcccccc}
\hline Rank & Genotype & $\begin{array}{c}\text { Total seed yield } \\
\text { (g pot-1) }(\mathrm{WS})\end{array}$ & $\begin{array}{c}\text { Relative total } \\
\text { seed yield }\end{array}$ & Genotype & $\begin{array}{c}\text { Total seed yield } \\
\text { (g pot-1) (WS) }\end{array}$ & $\begin{array}{c}\text { Relative total } \\
\text { seed yield }\end{array}$ \\
\hline & & Year 1 & & & Year 2 & \\
1 & ICC8950(T) & 2.22 & 0.76 & ICC3325(T) & 2.59 & 0.53 \\
2 & ICC14799(T) & 2.21 & 0.59 & ICC8950(T) & 1.90 & 0.40 \\
3 & ICC2263(T) & 2.08 & 0.64 & ICC14799(T) & 1.55 & 0.38 \\
4 & ICC3325(T) & 2.01 & 0.49 & ICC2263(T) & 1.26 & 0.40 \\
5 & ICC867(T) & 1.47 & 0.48 & ICC7184(S) & 1.16 & 0.63 \\
6 & ICC4814(S) & 1.15 & 0.39 & ICC3776(S) & 1.06 & 0.41 \\
7 & ICC7184(S) & 0.77 & 0.55 & ICC867(T) & 1.01 & 0.54 \\
8 & ICC3776(S) & 0.62 & 0.29 & ICC4814(S) & 0.58 & 0.47 \\
9 & ICC7323(S) & 0.44 & 0.31 & ICC7323(S) & 0.54 & 0.80 \\
10 & ICC8058(S) & 0.24 & 0.19 & ICC8058(S) & 0.50 & 0.20 \\
$F$-probability & - & $<0.001$ & $<0.001$ & - & $<0.001$ & 0.15 \\
1.s.d. & - & 0.57 & 0.19 & - & 0.63 & NA \\
\hline
\end{tabular}

scores found in the field and which were used to classify the genotypes into drought tolerant and drought sensitive genotypes in this study. The ranking of the total seed yield in the WS treatment did demonstrate that the group of putatively drought tolerant genotypes had higher total seed yield than the putatively drought sensitive genotypes in year 1 and in four of the five genotypes in year 2. However, the ranking of the relative values of total seed yield, phase I seed yield and phase II seed yield did not match the ranking of the absolute seed yield values in either of the years (Table 4; Table S3).

\section{Seed yields and seed yield components}

In the WW treatment, the phase I and phase II seed yields varied significantly among most of the genotypes in both years (Fig. 2) and this genetic variation was also apparent in the phase I and II 

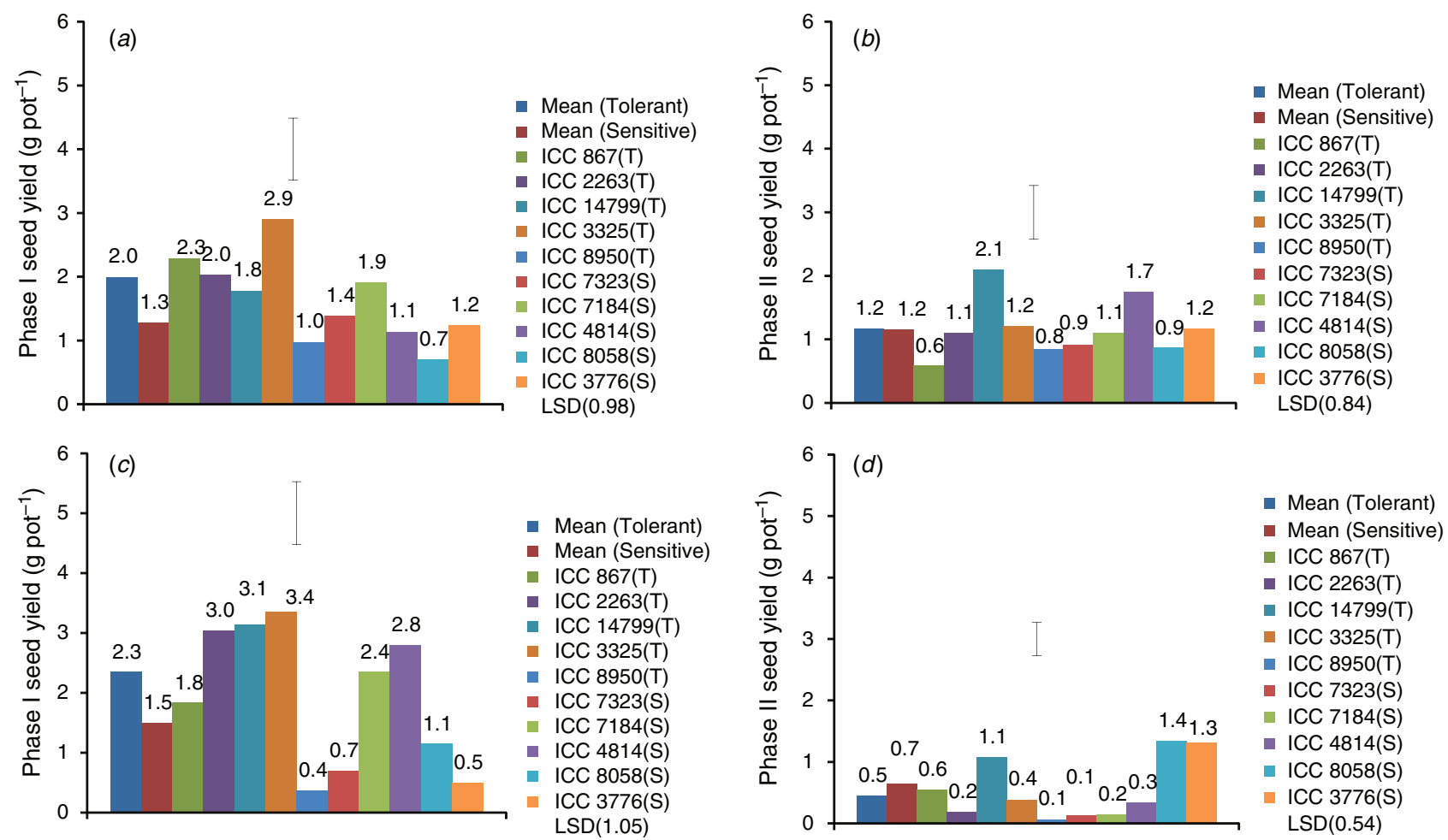

Genotype

Fig. 2. Mean chickpea seed yield $\left(\mathrm{g} \mathrm{pot}^{-1}\right)$ of the tolerant group, and sensitive group, and of the 10 genotypes during phase I ( $\left.a, c\right)$ and phase II $(b, d)$ in year $1(a, b)$ and year $2(c, d)$ in the well-watered (WW) treatment. Years 1 and 2 are not distinguished.

seed number in both years, in phase I flower number and in phase I flower + pod + seed abortion percentage, but not in phase II flower number and in phase II flower + pod + seed abortion percentage in both years (Tables 5, 6). Likewise, in the WS treatment, there were significant differences among the genotypes in total seed yield and in phase I and phase II seed yield (Fig. 3). There was also genetic variation in phase I and phase II seed number except in phase II, year 2, and in phase I flower + pod + seed abortion percentage, year 1 (Tables 5, 6).

\section{Relative total values of parameters to relative total seed yield}

The relative total seed number, i.e. the ratio of the total seed number in the WS treatment to that in the WW treatment was found to be closely related to the relative total seed yield in both the years $\left(R^{2}=0.83, R^{2}=0.79\right)($ Fig. 4$)$. By contrast, the relative total 100 -seed weight was not related to the relative total seed yield in both the years $\left(R^{2}=0.008, R^{2}=0.057\right)$ (data not shown). The relative total flower number was found to be significantly associated with relative total seed yield in year $2\left(R^{2}=0.23\right)$, but not in year $1\left(R^{2}=0.039\right)$, but the relative total flower + pod + seed abortion percentage was not associated with the relative total seed yield (drought tolerance) in either year $\left(R^{2}=0.002, R^{2}=0.009\right)$ (Table 7$)$. The relative harvest index also showed significant correlation to relative total seed yield in both the years $\left(R^{2}=0.39, R^{2}=0.53\right)$. The relative total pod number and relative total pod weight were also significantly correlated $\left(R^{2}=0.42\right.$ and 0.97 , year $1, R^{2}=0.80$ and
0.96, year 2) with relative total seed yield in both years (data not shown).

\section{Relative values of parameters in phases I and II to relative total seed weight}

In year 2 , the relative phase I pod number $\left(R^{2}=0.41\right)$, relative phase I flower number $\left(R^{2}=0.42\right)$, were found to be significantly and positively associated to relative total seed yield. The relative phase I seed number was associated with high relative total seed yield in both years $\left(R^{2}=0.46\right.$, year $1, R^{2}=0.45$, year 2$)$ and in phase II $\left(R^{2}=0.31\right.$, in year 1$)$, but not in year 2 , as very few seeds were set. Similarly, the relative total pod weight (i.e. the ratio of the pod weight in the WS treatment to that in the WW treatment) was more closely related to the relative phase I pod weight $\left(R^{2}=0.56\right.$, year $1, R^{2}=0.45$, year 2$)$, than in phase II $\left(R^{2}=0.44\right.$, in year 1$)$. The relative phase I seed number significantly contributed to relative phase I seed yield in both the years $\left(R^{2}=0.78\right.$, year $1, R^{2}=0.46$, year 2$)$ and a similar trend followed in phase II $\left(R^{2}=0.89\right.$, year $1, R^{2}=0.19$, year 2$)$ (Table 7). This suggests that the setting of a high seed number was important in the production of high seed yields when the stress was both mild and severe. The contribution of phase II seed yield to total seed yield was still significant, indicating that the number of seeds under severe stress conditions also contributed substantially to the total seed yield. The relative phase I flower number contributed more significantly ( $R^{2}=0.26$, year $1, R^{2}=0.46$, year 2 ) to relative phase I seed yield compared with the case in phase II $\left(R^{2}=0.11\right.$, year 1 , 
Table 5. Mean flower number $\operatorname{pot}^{-1}$, mean flower + pod + seed abortion $\% \operatorname{pot}^{-1}$, mean seed number pot ${ }^{-1}$ developed in Phase I (normalised transpiration rate between 1.0 and 0.50 ) and the aboveground harvest index (HI) of whole plants at maturity in the well-watered (WW) and waterstressed (WS) treatments in years 1 and 2

$\mathrm{T}$, tolerant; S, sensitive; NA, not applicable

\begin{tabular}{|c|c|c|c|c|c|c|c|c|c|}
\hline Phase & Genotype & $\begin{array}{l}\text { Flower } \\
\text { number }\end{array}$ & $\begin{array}{c}\text { Flower }+ \text { pod }+ \\
\text { seed abortion }(\%)\end{array}$ & $\begin{array}{c}\text { Seed } \\
\text { number }\end{array}$ & $\begin{array}{c}\text { Total } \\
\text { HI }\end{array}$ & $\begin{array}{l}\text { Flower } \\
\text { number }\end{array}$ & $\begin{array}{c}\text { Flower }+ \text { pod }+ \\
\text { seed abortion }(\%)\end{array}$ & $\begin{array}{c}\text { Seed } \\
\text { number }\end{array}$ & $\begin{array}{c}\text { Total } \\
\text { HI }\end{array}$ \\
\hline & & & WW & & & & WS & & \\
\hline \multicolumn{10}{|l|}{ Year 1} \\
\hline \multirow[t]{16}{*}{ Phase I } & ICC 867 (T) & 41.6 & 73.0 & 17.9 & 0.4 & 35.5 & 68.0 & 8.80 & 0.37 \\
\hline & ICC $2263(\mathrm{~T})$ & 29.9 & 25.8 & 16.3 & 0.45 & 18.0 & 55.6 & 10.7 & 0.35 \\
\hline & ICC $14799(\mathrm{~T})$ & 20.0 & 29.6 & 13.2 & 0.48 & 20.8 & 49.1 & 8.36 & 0.45 \\
\hline & ICC $3325(\mathrm{~T})$ & 35.9 & 31.9 & 22.7 & 0.52 & 21.3 & 56.2 & 10.3 & 0.43 \\
\hline & ICC $8950(\mathrm{~T})$ & 27.9 & 54.8 & 13.7 & 0.23 & 17.5 & 74.9 & 2.63 & 0.16 \\
\hline & ICC 7323 (S) & 28.1 & 61.3 & 14.8 & 0.37 & 27.2 & 52.0 & 10.4 & 0.21 \\
\hline & ICC 7184 (S) & 37.1 & 41.7 & 20.2 & 0.50 & 28.3 & 67.0 & 8.70 & 0.35 \\
\hline & ICC $4814(\mathrm{~S})$ & 14.3 & 21.4 & 11.2 & 0.48 & 20.5 & 55.5 & 10.2 & 0.38 \\
\hline & ICC $8058(\mathrm{~S})$ & 19.3 & 71.6 & 5.10 & 0.32 & 21.4 & 99.0 & 1.69 & 0.10 \\
\hline & ICC 3776 (S) & 17.7 & 40.6 & 11.7 & 0.35 & 20.7 & 82.0 & 4.10 & 0.13 \\
\hline & Mean tolerant & 31.1 & 43.0 & 16.8 & 0.42 & 22.6 & 60.8 & 8.15 & 0.35 \\
\hline & Mean sensitive & 23.3 & 47.3 & 12.6 & 0.41 & 23.6 & 71.1 & 7.02 & 0.23 \\
\hline & Mean 10 genotypes & 27.2 & 45.2 & 14.7 & 0.41 & 23.1 & 65.9 & 7.58 & 0.29 \\
\hline & Genotype ( $F$-probability) & 0.03 & 0.003 & 0.01 & $<0.001$ & 0.10 & 0.05 & 0.001 & $<0.001$ \\
\hline & 1.s.d. (Genotype) & 16.8 & 29.1 & 8.09 & 0.10 & NA & 29.4 & 4.73 & 0.10 \\
\hline & 1.s.d. (Treatment) & 14.1 & 27.8 & 6.29 & 0.10 & 14.1 & 27.8 & 6.29 & 0.10 \\
\hline \multicolumn{10}{|l|}{ Year 2} \\
\hline \multirow[t]{16}{*}{ Phase I } & ICC $867(T)$ & 27.7 & 53.0 & 15.3 & 0.36 & 17.0 & 52.2 & 9.03 & 0.44 \\
\hline & ICC $2263(\mathrm{~T})$ & 67.2 & 70.5 & 31.6 & 0.37 & 31.0 & 67.4 & 13.3 & 0.40 \\
\hline & ICC $14799(\mathrm{~T})$ & 60.5 & 55.2 & 30.7 & 0.34 & 50.4 & 70.9 & 17.8 & 0.32 \\
\hline & ICC $3325(\mathrm{~T})$ & 56.5 & 55.5 & 29.4 & 0.41 & 44.0 & 56.6 & 23.3 & 0.39 \\
\hline & ICC $8950(\mathrm{~T})$ & 11.9 & 68.3 & 3.38 & 0.07 & 19.1 & 72.1 & 4.06 & 0.15 \\
\hline & ICC 7323 (S) & 48.9 & 69.5 & 11.3 & 0.14 & 25.5 & 85.2 & 9.63 & 0.19 \\
\hline & ICC $7184(S)$ & 76.0 & 85.7 & 28.6 & 0.31 & 27.9 & 62.1 & 12.3 & 0.43 \\
\hline & ICC 4814 (S) & 79.5 & 59.2 & 32.2 & 0.36 & 47.8 & 73.0 & 21.7 & 0.38 \\
\hline & ICC 8058 (S) & 17.9 & 55.5 & 7.38 & 0.25 & 7.73 & 61.5 & 3.61 & 0.08 \\
\hline & ICC 3776 (S) & 17.7 & 63.1 & 5.85 & 0.27 & 23.9 & 70.2 & 8.67 & 0.33 \\
\hline & Mean tolerant & 44.8 & 60.5 & 22.1 & 0.31 & 32.3 & 63.9 & 13.5 & 0.34 \\
\hline & Mean sensitive & 48.0 & 66.6 & 17.1 & 0.27 & 26.6 & 70.4 & 11.2 & 0.28 \\
\hline & Mean 10 genotypes & 46.4 & 63.5 & 19.6 & 0.29 & 29.4 & 67.1 & 12.4 & 0.31 \\
\hline & Geno ( $F$-probability) & $<0.001$ & $<0.001$ & $<0.001$ & $<0.001$ & $<0.001$ & 0.52 & $<0.001$ & $<0.001$ \\
\hline & 1.s.d. (Genotype) & 28.4 & 17.5 & 11.2 & 0.1 & 19.6 & 27.6 & 6.63 & 0.16 \\
\hline & 1.s.d. (Treatment) & 22.9 & 23.4 & 8.20 & 0.13 & 22.9 & 23.4 & 8.20 & 0.13 \\
\hline
\end{tabular}

$R^{2}=0.09$, year 2) (Table 8) suggesting that the production of a high flower number under mild stress led to higher seed yield. However in both years, the relative total seed yield was more closely related to the relative phase I seed yield than to the relative phase II seed yield, indicating that most of the genetic variation for the sensitivity of the reproductive phase to water stress was expressed under a mild water stress (Tables 7,8 ).

\section{Discussion}

Comparison of drought tolerance/sensitivity in this glasshouse study with previous measures of drought tolerance/sensitivity in the field

In the WS treatment, the total seed yield of the genotypes that were observed to be higher yielding when exposed to terminal drought in the field remained higher than most of the sensitive genotypes in the present study (Fig. 3). This was also true for the phase I seed yield, but was not the case when measured in the pods produced in phase II when the stress was more severe. It is noted that several of the sensitive genotypes had also a poor yield under WW conditions, suggesting that part of the differences under WS conditions was explained by differences in the yield potential. Thus, the relative values were calculated for each parameter. The ranking for relative total seed yield differed from the ranking of absolute yields in the field in both years indicating that the yield potential of genotypes explained in part the performance of the genotypes under stress conditions. Therefore, we used the relative values to analyse the possible causes for reproductive success in the drought-tolerant genotypes.

\section{Effect of drought on reproduction (flower, seed and pod numbers)}

The maintenance of a high flower, pod and seed number led to high seed yield in this study (Fig. 4). There was a very significant 
Table 6. Mean flower number $\operatorname{pot}^{-1}$, mean flower + pod + seed abortion $\% \operatorname{pot}^{-1}$, mean seed number pot ${ }^{-1}$ developed in phase II (normalised transpiration rate between 0.49 and 0.10 ) in the well-watered (WW) and water-stressed (WS) treatments in years 1 and 2 $\mathrm{T}$, tolerant; S, sensitive; NA, not applicable

\begin{tabular}{|c|c|c|c|c|c|c|c|}
\hline Phase & Genotype & $\begin{array}{l}\text { Flower } \\
\text { number }\end{array}$ & $\begin{array}{c}\text { Flower }+ \text { pod }+ \\
\text { seed abortion }(\%)\end{array}$ & $\begin{array}{c}\text { Seed } \\
\text { number }\end{array}$ & $\begin{array}{l}\text { Flower } \\
\text { number }\end{array}$ & $\begin{array}{c}\text { Flower }+ \text { pod }+ \\
\text { seed abortion }(\%)\end{array}$ & $\begin{array}{c}\text { Seed } \\
\text { number }\end{array}$ \\
\hline & & & WW & & & WS & \\
\hline \multicolumn{8}{|l|}{ Year 1} \\
\hline \multirow[t]{16}{*}{ Phase II } & ICC $867(\mathrm{~T})$ & 19.6 & 80.0 & 4.45 & 11.2 & 89.7 & 1.53 \\
\hline & ICC $2263(\mathrm{~T})$ & 19.0 & 46.7 & 8.21 & 15.2 & 72.0 & 5.53 \\
\hline & ICC $14799(\mathrm{~T})$ & 27.7 & 54.5 & 15.9 & 22.0 & 67.3 & 8.17 \\
\hline & ICC $3325(\mathrm{~T})$ & 28.5 & 76.8 & 10.5 & 16.7 & 76.5 & 4.07 \\
\hline & ICC $8950(\mathrm{~T})$ & 30.9 & 63.2 & 9.75 & 6.43 & 72.2 & 1.13 \\
\hline & ICC $7323(\mathrm{~S})$ & 23.4 & 72.9 & 9.73 & 14.8 & 74.0 & 1.61 \\
\hline & ICC $7184(\mathrm{~S})$ & 29.3 & 74.4 & 9.54 & 8.76 & 92.4 & 1.95 \\
\hline & ICC 4814 (S) & 35.4 & 45.3 & 15.3 & 15.8 & 81.1 & 8.33 \\
\hline & ICC $8058(\mathrm{~S})$ & 15.4 & 69.1 & 4.80 & 13.2 & 98.6 & 0.15 \\
\hline & ICC $3776(S)$ & 25.5 & 74.8 & 12.6 & 10.5 & 81.6 & 1.90 \\
\hline & Mean tolerant & 25.1 & 64.2 & 9.76 & 14.3 & 75.5 & 4.09 \\
\hline & Mean sensitive & 25.8 & 67.3 & 10.4 & 12.6 & 85.5 & 2.79 \\
\hline & Mean 10 genotypes & 25.5 & 65.8 & 10.1 & 13.5 & 80.5 & 3.44 \\
\hline & Genotype ( $F$-probability) & 0.1 & 0.18 & 0.01 & 0.1 & 0.03 & $<0.001$ \\
\hline & 1.s.d. (Genotype) & NA & NA & 6.11 & NA & 19.4 & 3.71 \\
\hline & 1.s.d. (Treatment) & 11.7 & 24.7 & 4.85 & 11.67 & 24.7 & 4.85 \\
\hline \multicolumn{8}{|l|}{ Year 2} \\
\hline \multirow[t]{16}{*}{ Phase II } & ICC $867(\mathrm{~T})$ & 25.9 & 76.5 & 4.11 & 2.84 & 81.5 & 0.74 \\
\hline & ICC $2263(\mathrm{~T})$ & 32.6 & 86.5 & 2.51 & 3.08 & 96.4 & 0.09 \\
\hline & ICC $14799(\mathrm{~T})$ & 49.1 & 79.0 & 9.07 & 12.3 & 99.8 & 0.19 \\
\hline & ICC $3325(\mathrm{~T})$ & 29.6 & 81.3 & 3.08 & 7.32 & 85.1 & 0.83 \\
\hline & ICC $8950(\mathrm{~T})$ & 33.0 & 85.6 & 1.53 & 8.64 & 87.9 & 0.80 \\
\hline & ICC $7323(S)$ & 45.8 & 96.6 & 2.21 & 15.1 & 74.0 & 0.84 \\
\hline & ICC $7184(\mathrm{~S})$ & 18.8 & 93.7 & 4.54 & 7.08 & 99.1 & 0.32 \\
\hline & ICC $4814(\mathrm{~S})$ & 40.4 & 73.8 & 3.08 & 4.58 & 91.2 & 0.08 \\
\hline & ICC 8058 (S) & 71.7 & 82.9 & 7.38 & 14.1 & 73.8 & 1.64 \\
\hline & ICC 3776 (S) & 49.3 & 76.2 & 15.8 & 23.1 & 82.8 & 3.33 \\
\hline & Mean tolerant & 31.6 & 81.8 & 4.06 & 6.84 & 90.1 & 0.53 \\
\hline & Mean sensitive & 43.3 & 84.6 & 6.59 & 12.8 & 84.2 & 1.24 \\
\hline & Mean 10 genotypes & 39.6 & 83.2 & 5.33 & 9.82 & 87.1 & 0.89 \\
\hline & Genotype ( $F$-probability) & 0.01 & 0.14 & $<0.001$ & 0.29 & 0.17 & 0.4 \\
\hline & 1.s.d. (Genotype) & 26.2 & NA & 5.68 & NA & NA & NA \\
\hline & 1.s.d. (treatment) & 20.1 & 22.9 & 3.89 & 20.13 & 22.9 & 3.89 \\
\hline
\end{tabular}

and strong positive relationship between the relative total seed number and relative total yield in both years (Fig. 4). As relative seed size did not vary, the role of seed number in determining yield was clearly important. The variation in relative seed number among genotypes was largely the result of the variation in the relative flower number. There was a positive relationship between the relative total seed yield and the relative total flower number at least in 1 year (year 2) (Tables 7, 8), and also clear relationships between the flower number produced in phase I and the relative seed yield produced in that phase in both years. In contrast, there was no association between the relative total seed yield and the relative total flower + pod + seed abortion in either of the years. Therefore, the genotypes that achieved high yields in the water stress treatment were those producing a large number of flowers, but not those that aborted fewer flowers + pods + seeds. The ability to produce a high number of flowers was particularly important in the phase I (the mild stress) (Tables 7,8) and this led to higher phase I seed yield and thus overall. Chickpea as an indeterminate crop that continues to produce flowers, pods and set seeds while water is available (Croser et al. 2003). When the plants undergo water shortage, our results suggest that continuing to produce a high number of flowers and pods during the initial phase of mild water stress was a key factor in enhancing yield. Production of a large number of flowers was also found to be a key yield determinant under saline stress in chickpea (Vadez et al. 2012). These findings could be somewhat counterintuitive - we would expect that a lower seed/pod abortion rate would be more favourable. The results may therefore suggest that the key step in the reproductive process is to successfully fertilise flowers and generate a young fertile embryo. The production of many flowers would indeed increase the chances of success of that key step. This would of course need further research. 


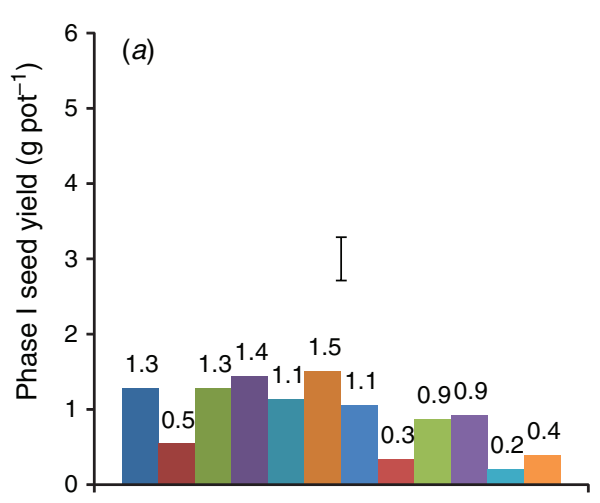

- Mean Tolerant

- Mean Sensitive

- ICC $867(T)$

- ICC 2263(T)

- ICC 14799(T)

- ICC 3325(T)

- ICC 8950(T)

- ICC 7323(S)

- ICC 7184(S)

- ICC 4814(S)

- ICC 8058(S)

- ICC $3776(\mathrm{~S})$

$\operatorname{LSD}(0.58)$

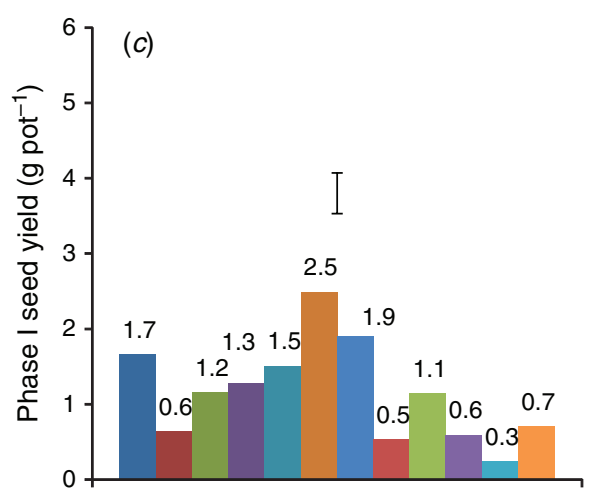

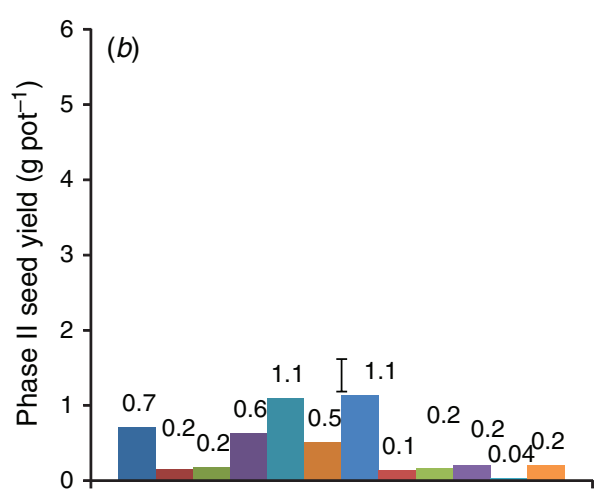

- Mean Tolerant

- Mean Sensitive

- ICC 867(T)

- ICC 2263(T)

- ICC 14799(T)

- ICC 3325(T)

- ICC 8950(T)

- ICC 7323(S)

- ICC 7184(S)

- ICC 4814(S)

- ICC 8058(S)

- ICC $3776(\mathrm{~S})$ $\operatorname{LSD}(0.43)$

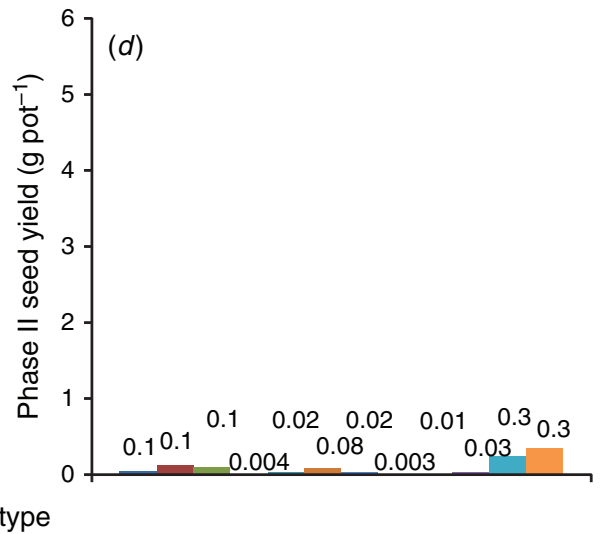

- Mean Tolerant

- Mean Sensitive

- ICC 867(T)

- ICC 2263(T)

- ICC 14799(T)

- ICC 3325(T)

- ICC 8950(T)

- ICC 7323(S)

- ICC 7184(S)

- ICC 4814(S)

- ICC 8058(S)
- ICC 3776(S)

Fig. 3. Mean chickpea seed yield $\left(\mathrm{g} \mathrm{pot}^{-1}\right)$ in the tolerant group and sensitive group and of the 10 genotypes during phase I $(a, c)$ and phase II $(b, d)$ in year $1(a, b)$ and year $2(c, d)$ in the water-stressed (WS) treatment.
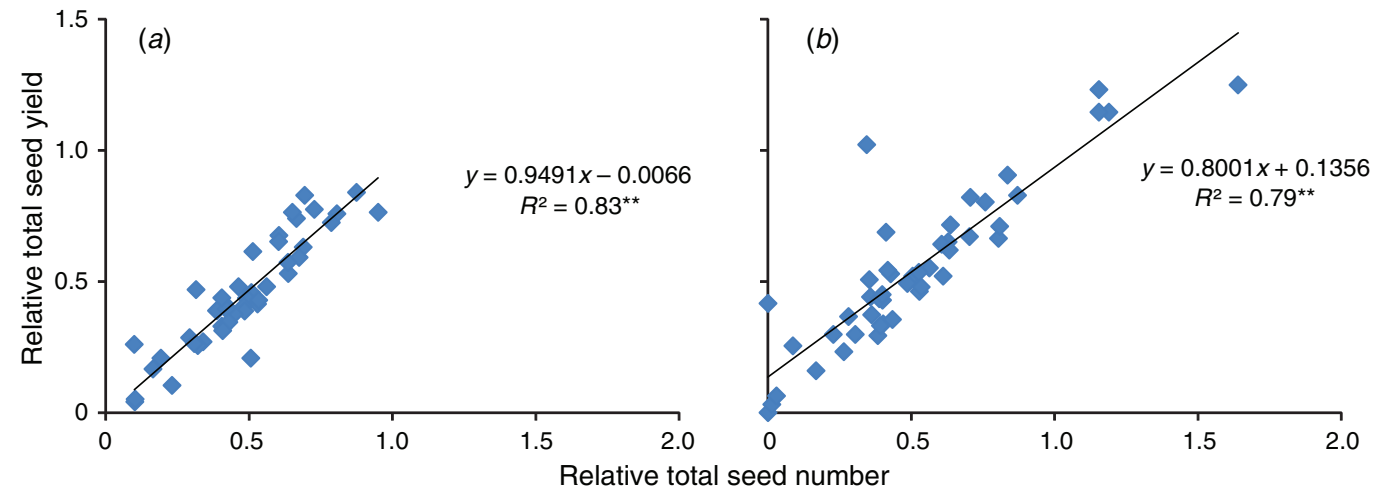

Fig. 4. Relationships between relative total chickpea seed number and relative total seed yield in year $1(a)$ and year $2(b)$.

The fact that there was only a weak association between the relative phase II seed yield and the relative phase II flower number indicated that much of the discriminatory effect of drought took place under mild stress conditions. Ontogenetic effects on flower production observed in both the WW and WS treatments presumably contributed to the poor association between flower number and seed yield in phase II. Moreover, in the present study, the later-formed flowers/pods had a $20 \%$ higher abortion percentage than the early-formed ones in waterlimited environments in both the years in agreement with Fang et al. (2010). The ability of flowers to set pods is influenced by several environmental factors in addition to cultivar, and a large proportion $(50-80 \%)$ of flowers do not develop pods even under WW conditions (Clarke and Siddique 1998; Fang et al. 2010). As the environmental conditions in the glasshouse and the development of the water stress in phase I was similar in all genotypes, the differences in flower and seed production was largely genetic and this genetic variation in flower production in response to mild stress is clearly worthy of further investigation. 
Table 7. Relationship between relative total seed yield (RTSY) and relative total values of flower number in year 1, flower number in year 2 , flower + pod + seed abortion \% in year 1, flower + pod + seed abortion \% in year 2 , phase I seed yield in year 1, phase I seed yield in year 2, phase II seed yield in year 1, phase II seed yield in year 2, phase I flower number in year 2, phase I pod number in year 2 for 10 genotypes

Equations are the fitted linear regressions with the correlation coefficients and level of significance: * $P<0.05 ; * *, P<0.01 ;$ n.s., not significant at $P=0.05$

\begin{tabular}{|c|c|}
\hline Factor & Linear relationship \\
\hline Relative total flower number-year 1 (RTFNY1) & $\mathrm{RTSY}=0.1617 x+0.365 \mathrm{RTFNY} 1, r^{2}=0.0319 \mathrm{n} . \mathrm{s}$ \\
\hline Relative total flower number-year 2 (RTFNY2) & $\mathrm{RTSY}=0.6444 x+0.1971 \mathrm{RTFNY} 2, r^{2}=0.23 * *$ \\
\hline Relative total flower + pod + seed abortion $\%$ in year 1 (RFlPdAbY 1$)$ & $\mathrm{RTSY}=-0.0249 x+0.5247 \mathrm{RF} 1 \mathrm{PdAbY} 1, r^{2}=0.0026 \mathrm{n} . \mathrm{s}$ \\
\hline Relative total flower + pod + seed abortion $\%$ in year $2($ RFlPdAbY2) & $\mathrm{RTSY}=0.1317 x+0.3852 \mathrm{RF} 1 \mathrm{PdAbY} 2, r^{2}=0.0092 \mathrm{n} . \mathrm{s}$ \\
\hline Relative phase I seed yield in year 1 (RPhISYY1) & RTSY $=0.6034 x+0.1205$ RPhISYY $1, r^{2}=0.69 * *$ \\
\hline Relative phase I seed yield in year 2 (RPhISYY2) & RTSY $=0.6868 x+0.0738$ RPhISYY $2, r^{2}=0.76 * *$ \\
\hline Relative phase II seed yield in year 1 (RPhIISYY1) & RTSY $=0.3916 x+0.3693 \mathrm{RPhIISYY} 1, r^{2}=0.31^{*}$ \\
\hline Relative phase II seed yield in year 2 (RPhIISYY2) & RTSY $=0.066 x+0.066 \mathrm{RPhIISYY} 2, r^{2}=0.0091 \mathrm{n} . \mathrm{s}$ \\
\hline Relative phase I flower number in year 2 (RPhIFNY2) & RTSY $=1.0718 x+0.1595 \mathrm{RPhIFNY} 2, r^{2}=0.42 * *$ \\
\hline Relative phase I pod number in year 2 (RPhIPNY2) & RTSY $=0.7219 x+0.1636 \mathrm{RPhIPNY} 2, r^{2}=0.42 * *$ \\
\hline
\end{tabular}

Table 8. Relationship between relative phase I seed yield (RSY-Ph1) and relative values (per pot) of phase I flower number-year 1, phase I flower number-year2, phase II flower number-year 1, phase II flower number-year 2 for 10 genotypes

Equations are the fitted linear regressions with the correlation coefficients and level of significance $(* *, P<0.01$; n.s., non-significant at $P=0.05$

\begin{tabular}{ll}
\hline Factor & Linear relationship \\
\hline Relative phase I flower number in year 1 (RPhIFNY1) & RSY-Ph1 $=0.3424 x+0.2755$ RPIFNY1, $r^{2}=0.26^{* *}$ \\
Relative phase I flower number in year 2 (RPhIFNY2) & RSY-Ph1 $=0.5711 x+0.2588$ R PhIFNY2, $r^{2}=0.46^{* *}$ \\
Relative phase II flower number in year 1 (RPhIIFNY1) & RSY-Ph1 $=0.2481 x+0.2373$ RPIIFNY1, $r^{2}=0.12^{* *}$ \\
Relative phase II flower number in year 2 (RPhIIFNY2) & RSY-Ph1 $=0.2982 x+0.0552$ RPhIIFNY2, $r^{2}=0.0939$ n.s \\
\hline
\end{tabular}

The 100-seed weight in both the mild and severe WS was not affected by the WS treatment compared with the WW treatment, indicating that the seed filling was maintained under the controlled water stress conditions of this study. This suggests that once the seed enters the phase of rapid dry weight accumulation, the young seeds already developed had priority for assimilates rather than the small seeds early in their development. Also, during seed development, the decrease in source : sink ratio may increase the abortion of young pods, but not the rate of seed growth in filling pods (Turner et al. 2005).

Therefore, reproductive success in a water-limited environment appears to be linked to the capacity to produce a large number of flowers and retain a high number of fertile seeds, while maintaining the filling of these seeds. These results are very similar to the finding of Vadez et al. (2012) where the salinity tolerance was determined by maintenance of relatively large number of seeds in early and late- flowering chickpea genotypes.

\section{Genotypic variation in threshold values - value of the dry down method}

Previously water deficit and terminal drought studies have been carried out at both the vegetative and reproductive stages (Leport et al. 2006; Fang et al. 2010, 2011; Krishnamurthy et al. 2010; Zaman-Allah et al. 2011a, 2011b). In this study, the water stress was gradually imposed to 10 genotypes from the onset of flowering. The slow dry down by re-watering to the same soil water level in all genotypes overcomes the drawback of simply imposing a water deficit by withholding water when plants vary in leaf area and rates of transpiration and are then exposed to different rates of development of water deficit (Harb et al. 2010). The fact that we found a different ranking in the relative seed yield in these experiments and in the field indicate that we revealed specific sensitivities of genotypes to a controlled water stress imposed during reproduction. For instance, field tolerant ICC867 had ranking values close or equal to those of the sensitive genotypes, indicating that this genotype must have its reproductive stage particularly sensitive to the application of a water stress. In contrast, field sensitive ICC7184 had high relative seed yield values, indicating that the low yield of this genotype in the field was not related to the sensitivity of its reproduction to drought.

The FTSW threshold values, measured here during the reproductive phase, tended to be slightly higher than those reported by Zaman-Allah et al. (2011b), measured in the vegetative phase of chickpea. In our study, although we found higher levels of genotypic variation among genotypes in $t$, the threshold values did not differ between the putatively tolerant and putatively sensitive genotypes either based on absolute or relative total seed yield as also observed under glasshouse conditions by Zaman-Allah et al. (2011b). Although the rates of development of water deficit were similar among genotypes within years in the present study, they were not identical 
across years, in part because of plant size differences across years, probably caused by differences in environmental conditions such as radiation or vapour pressure deficit that were not controlled in the glasshouse. However, these environmental differences had little effect on yield, which was mostly driven by genotypic variation, but had a substantial interaction effect on the parameters, seed number and flower number.

\section{Conclusion}

The slow dry down approach used in this study was a useful methodology for controlling the WS treatment imposition in pots in the glasshouse and for the imposition of similar intensities of water deficit across genotypes irrespective of plant size. Although the ranking for total seed yield under WS in this work did not correspond with the total seed yield ranking in the field, particularly when differences in potential yield were taken into account. We consider that this was the result of a large genotype $\times$ environment interaction that was evident not only between the field and glasshouse, but also between years. From the relative parameter values, genotypic differences in total and phase I seed yield under WS conditions were mostly driven by the number of flowers produced and the number of seeds that were set under the mild stress conditions, but not by the total flower + pod + seed abortion percentage or the 100 -seed weight. Seed size (100-seed weight) was conserved across treatments suggesting that seed set was adjusted to maintain seed size and viability. The factors that determine the genetic variation in flower production and seed set as water deficits develop requires further investigation.

\section{Acknowledgements}

The authors thank Australia-India Strategic Research Fund (Project ST050162), the Australian Research Council (Linkage project LP0776586) and the Council of Grain Growers Organisation for financial support. R Pushpavalli thanks the World Bank for financial support through a grant from the International Fund for Agriculture Research (IFAR).

\section{References}

Berger JD, Turner NC, Siddique KHM, Knights EJ, Brinsmead RB, Mock I, Edmondson C, Khan TN (2004) Genotype by environment studies across Australia reveal the importance of phenology for chickpea (Cicer arietinum L.) improvement. Australian Journal of Agricultural Research 55, 1071-1084. doi:10.1071/AR04104

Clarke HJ, Siddique KHM (1998) Growth and development. In 'The Chickpea book: a technical guide to chickpea production. Bulletin 1326'. (Eds SP Loss, N Brandon, KHM Siddique) pp. 3-10. (Department of Agriculture of Western Australia: South Perth)

Croser JS, Clarke HJ, Siddique KHM, Khan TN (2003) Low temperature stress: implications for chickpea (Cicer arietinum L.) improvement. Critical Reviews in Plant Sciences 22, 185-219. doi:10.1080/713610855

Davies SL, Turner NC, Siddique KHM, Plummer JA, Leport L (1999) Seed growth of desi and kabuli chickpea (Cicer arietinum L.) in a short-season Mediterranean-type environment. Australian Journal of Experimental Agriculture 39, 181-188. doi:10.1071/EA98134

Davies SL, Turner NC, Palta JA, Siddique KHM, Plummer JA (2000) Remobilization of carbon and nitrogen supports seed filling in chickpea subjected to water deficit. Australian Journal of Agricultural Research 51, 855-866. doi:10.1071/AR00018

Fang X, Turner NC, Yan G, Li F, Siddique KHM (2010) Flower numbers, pod production, pollen viability, and pistil function are reduced and flower and pod abortion increased in chickpea (Cicer arietinum L.) under terminal drought. Journal of Experimental Botany 61, 335-345. doi:10.1093/jxb/erp307

Fang XW, Turner NC, Li FM, Siddique KHM (2011) An early transient water deficit reduces flower number and pod production but increases seed size in chickpea (Cicer arietinum L.) Crop and Pasture Science 62, 481-487. doi:10.1071/CP10349

FAOSTAT (2013) FAOSTAT database. Available at http://faostat3.fao.org/ faostat-gateway/go/to/download/Q/QC/E [Verified 12 August 2014]

Gowda CLL, Parthasarathy Rao P, Tripathy S, Gaur PM, Deshmukh RB (2009) Regional shift in chickpea production in India. In 'Milestones in food legumes research'. (Eds A Masood, S Kumar) pp. 21-35. (Indian Institute of Pulses Research: Kanpur, India)

Harb A, Krishnan A, Ambavaram MMR, Pereira A (2010) Molecular and physiological analysis of drought stress in Arabidopsis reveals early responses leading to acclimation in plant growth. Plant Physiology 154, 1254-1271. doi:10.1104/pp.110.161752

Krishnamurthy L, Kashiwagi J, Gaur PM, Upadhyaya HD, Vadez V (2010) Sources of tolerance to terminal drought in the chickpea (Cicer arietinum L.) minicore germplasm. Field Crops Research 119, 322-330. doi:10.1016/j.fcr.2010.08.002

Leport L, Turner NC, French RJ, Tennant D, Thomson BD, Siddique KHM (1998) Water relations, gas exchange and growth of cool-season grain legumes in a Mediterranean-type environment. European Journal of Agronomy 9, 295-303. doi:10.1016/S1161-0301(98)00042-2

Leport L, Turner NC, French RJ, Barr MD, Duda R, Davies SL, Tennant D, Siddique KHM (1999) Physiological responses of chickpea genotypes to terminal drought in a Mediterranean-type environment. European Journal of Agronomy 11, 279-291. doi:10.1016/S1161-0301(99) 00039-8

Leport L, Turner NC, Davies SL, Siddique KHM (2006) Variation in pod production and abortion among chickpea cultivars under terminal drought. European Journal of Agronomy 24, 236-246. doi:10.1016/j. eja.2005.08.005

Ray JD, Sinclair TR (1998) The effect of pot size on growth and transpiration of maize and soybean during water deficit stress. Journal of Experimental Botany 49, 1381-1386. doi:10.1093/jxb/49.325.1381

Siddique KHM, Brinsmead RB, Knight R, Knights E, Paull JG, Rose IA (2000) Adaptation of chickpea (Cicer arietinum L.) and faba bean (Viciafaba L.) to Australia. In 'Linking research and marketing opportunities for pulses in the 21 st century'. (Ed. R Knight) pp. 289-303. (Kluwer Academic Publishers: Dordrecht, The Netherlands)

Sinclair TR, Ludlow MM (1985) Who taught plants thermodynamics? The unfulfilled potential of plant water potential. Australian Journal of Plant Physiology 12, 213-217. doi:10.1071/PP9850213

Turner NC (2003) Adaptation to drought: lessons from studies with chickpea. Indian Journal of Plant Physiology (Special issue), 11-17.

Turner NC, Davies SL, Plummer JA, Siddique KHM (2005) Seed filling in grain legumes under water deficits, with emphasis on chickpeas. Advances in Agronomy 87, 211-250. doi:10.1016/S0065-2113(05) 87005-1

Upadhyaya HD, Ortiz R (2001) A mini-core subset for capturing diversity and promoting utilization of chickpea genetic resources in crop improvement. Theoretical and Applied Genetics 102, 1292-1298. doi:10.1007/s00122-001-0556-y

Upadhyaya HD, Dwivedi SL, Baum M, Varshney RK, Udupa SM, Gowda CLL, Hoisington D, Singh S (2008) Genetic structure, diversity, and allelic richness in composite collection and reference set in chickpea (Cicer arietinum L.). BMC Plant Biology 8, 106doi:10.1186/1471-22298-106 
Vadez V, Sinclair TR (2001) Leaf ureide degradation and $\mathrm{N}_{2}$ fixation tolerance to water deficit in soybean. Journal of Experimental Botany 52, 153-159. doi:10.1093/jexbot/52.354.153

Vadez V, Rashmi M, Sindhu K, Muralidharan M, Pushpavalli R, Turner NC, Krishnamurthy L, Gaur PM, Colmer TD (2012) Large number of flowers and tertiary branches, and higher reproductive success increase yields under salt stress in chickpea. European Journal of Agronomy 41, 42-51. doi:10.1016/j.eja.2012.03.008
Zaman-Allah M, Jenkinson DM, Vadez V (2011a) A conservative pattern of water use, rather than deep or profuse rooting, is critical for the terminal drought tolerance of chickpea. Journal of Experimental Botany 62, 4239-4252. doi:10.1093/jxb/err139

Zaman-Allah M, Jenkinson DM, Vadez V (2011b) Chickpea genotypes contrasting for seed yield under terminal drought stress in the field differ for traits related to the control of water use. Functional Plant Biology 38, 270-281. doi:10.1071/FP10244 